\title{
The Case of an Agricultural Crop Business Association in Navarra as Circular Economy Intermediary
}

\author{
Vanessa Prieto-Sandoval ${ }^{1}$ (D) $\cdot$ Andres Mejia-Villa $^{2} \cdot$ Carmen Jaca $^{3} \cdot$ Marta Ormazabal $^{3}$
}

Received: 23 November 2020 / Accepted: 16 September 2021 / Published online: 12 November 2021

(C) The Author(s), under exclusive licence to Springer Nature Switzerland AG 2021

\begin{abstract}
The circular economy (CE) is an alternative economic system based on closing energy and material cycles to achieve sustainable development and create value based on innovation. In this sense, business associations (BAs) can work as intermediaries to promote $\mathrm{CE}$ in industrial sectors. They bring together many companies, generate trustbased relationships, support companies' strategy and collaborative innovation to construct closed-loop material flows, and increase competitiveness in sectors and regions. This study aims to show the BA's role as intermediaries of CE and promoters of industrial symbiosis (IS) as a value creation strategy among its affiliated companies (AC). Thus, this work takes the form of an exploratory case study of five different companies of the Union of Agricultural Cooperatives of Navarra (UCAN) in Spain. Researchers collected this study's data through a focus group and surveys. As a result, an original serious game was developed in 2016 and a survey in 2016 and 2020, which considers the CE's six fields of action (take, make, manufacture, distribution, use, recovery, and IS). Finally, this study proposes a methodology to promote the CE through the BAs, based on the performance of the UCAN as an intermediary of the CE and IS. Likewise, BAs' potential to promote the closure of energy and materials cycles in regions and commercial sectors such as agribusiness is demonstrated. The study also demonstrated the organizations' evolution and the improved perception of economic benefits and reduced barriers to implementing CE. This long-term analysis is valuable in novel topics such as CE.
\end{abstract}

Keywords Business associations · Circular economy intermediaries · Industrial symbiosis · Agricultural crop sector · Serious games

Vanessa Prieto-Sandoval

juliethv.prieto@javeriana.edu.co

1 Business Department, Pontificia Universidad Javeriana, Bogotá, Colombia

2 Universidad de La Sabana, The International School of Economics and Administrative Sciences, Chía, Colombia

3 TECNUN School of Engineering, University of Navarra, San Sebastián, Spain 


\section{Introduction}

The circular economy (CE) is an alternative economic system based on closing the loops of energy and materials at macro, meso, and micro level systems, achieving sustainable development, and creating value based on innovation [1]. To apply this at the organizational level, Ormazabal et al. [2] define six CE fields of action to implement the CE: Take, make, distribution, use, recovery, and industrial symbiosis (IS). "Take" is related to the materials and energy supply, "make" is referring to the product design and sustainable transformation processes, then "distribution" considers every logistic, packaging, and value delivery process, "use" considers the product performance. Finally, a longer product life cycle and "recovery" aim to close the biological and technical loops. The latter field is considered transversal because Chertow [3] (p. 314) points out that IS is "the activity that engages traditionally separate industries in a collective approach to competitive advantage involving the physical exchange of materials, energy, water, and by-products." Although its name is more than 20 years old (and much older in practice), in the last five or six years, IS has become a subfield of a new concept, the Circular Economy (CE) [4]. Thus, at IS, organizations should work together to develop a business strategy to close those loops, and every CE activity requires the organization's integration with consumers and other stakeholders [2].

The Organisation for Economic Co-operation and Development (OECD) highlights the business associations' (BAs) role to boost CE in industrial sectors. They support the firms' strategy and collaborative innovation to facilitate the closed-loop of materials and increase competitiveness. Berkowitz and Dumez [5] explain the "increase of major contemporary societal problems, such as sustainable development in its environmental, economic, and social dimensions, human rights, and corporate social responsibility" in line with these inter-organizational and collaborative actions releases collective action at the global level. Daddi and Iraldo [6] research shows increased materials efficiency and economic benefits in Italy's IS experiences. Moreover, the National Strategy on CE launched in 2010 in Colombia engaged the national government and 30 leading BAs through a signed agreement that ensured their sectors' participation based on research, innovation, and economic incentives [7]. In Mexico, IPCA is an agro-industrial association formed by more than 350 smallholders and two "ejidos" or communal land organizations that involve at least 1000 ha of xoconostle crops available throughout the year does not fall off the cactus until it is collected. IPAC has managed to intermediate innovation through a flow of synergies to take advantage of all the xoconostle components and create value-added products such as wheat flour in the baking industry, jams, sauces, sweets, juices, staples, animal feed, and more [8]. All these arguments express the relevance of BA for making possible IS and CE implementation.

In this regard, Alfaro et al. [9] explain that BAs are more than organizations with a representative role. As Van Lente et al. [10] and Dalziel and Yao (2010) expressed, they are genuinely innovation intermediaries. Thus, for Gassmann et al. [11], innovation intermediaries are external institutions that support companies in their innovative activities; and they also explain that intermediary is an all-inclusive term that includes a company that delivers an innovative service to a customer in a variety of industries. More precisely, Howells [12] (p.720) defined it as "an organization or body that acts as an agent or broker in any aspect of the innovation process between two or more parties. Such intermediary activities include helping to provide information about potential 
collaborators, brokering a transaction between two or more parties, acting as a mediator or go-between, bodies or organizations that are already collaborating, and helping find advice, funding, and support for the innovation outcomes of such collaborations". Thus, BAs are key mechanisms for a transition towards more sustainable economic practice and drivers that can play an essential role in contributing to positive social change and addressing social and environmental issues [13]. It is also essential to research trends and progress over a more extended period to obtain longitudinal data on the evolution of $\mathrm{CE}$ adoption in companies [14].

Concerning BAs, Dalziel [15] (p.193) classifies them as nonprofit organizations with a significant impact (positive or negative) on their members' ability to innovate. She denominates them as "innovation-related nonprofits" whose mandates are scientific, technological, or business-related. Thus, Dalziel $[15,16]$ defines BAs as facilitators of innovation in games of innovation because they have (1) a high degree of knowledge; (2) specific structures to capture the value; and (3) focus on specific demands of market niches [17]. From a political, socio/ cultural, and technical perspective, Hutson [18] highlights industry associations' active role throughout the eco-innovation process.

Furthermore, Dalziel [15, 16] and Watkins et al.[19] present the benefits of BAs in innovation ecosystems. Many practical studies corroborate this statement. For example, Athreye and Chaturvedi [20] argue that industry associations play an essential role in developing countries, often compensating for inadequacies in the business environment. Thus, they present the positive effects of them in some cases in India. Other cases are the BAs in the Nigerian industry [21], the Brazilian associations [22], and Crespi et al. [23] present the relevant role of the Colombian Association of Flower Exporters. In developed countries, the role of BAs is also essential and evidenced through studies such as Canadian BAs [16]; the BAs from Denmark, Finland, and Hong Kong [24]; and associations from Germany, Norway, and Japan [25]. Likewise, Kautto [26] shows how companies work with prominent European BAs to build coalitions.

The relationships between companies are necessary to facilitate value creation, especially for capturing value by closing the loops of material and energy, as CE proposes. In that context, BAs can provide access to information and resources needed to develop new processes and products under the C's principles. Unfortunately, few studies relate the BAs of the agribusiness sector with the CE. As evidence, a search on Web of Science looking for Topic ("Circular Economy”) AND Topic: (“Agro*”) AND Topic: (cooperative*) only shows two results.

This study aims to support BAs to boost the CE as a value creation strategy among their ACs. This study's central question asks how BAs may become CE intermediaries? Thus, this study analyzes the case of a BA focus on the agricultural crop sector, UCAN (association of agricultural crop cooperatives of Navarra), which has promoted CE among its members and five affiliated companies. This research is novel for several reasons. First, it determines the role of the BAs in the CE. Second, few studies do a long-term follow-up on organizations' evolution in $\mathrm{CE}$ implementation, and third, it proposes a methodology and accompanying techniques such as serious games to take advantage of CE opportunities.

This paper is divided into five sections. Section 2 discusses the role of BAs and clusters for the CE. Section 3 describes the research method used to find answers to the research question. Section 4 analyzes the outcomes obtained in this research. Finally, Section 5 concludes with a summary of the main research results. 


\section{The General Role of BAs}

Dalziel [15] expresses that organizations as BAs have a transactional (market practices) or institutional (support and coordination activities) role (see Figure 1). Under the first role, agents can perform one of the following functions vis-à-vis the focal company (any particular company): customer, supplier, competitor, or complement. The second role is associated with organizations that accomplish institutional functions of an economic or social nature, that is, functions focused on supporting, coordinating, and helping other companies. BAs are examples of both roles because they participate in the market dynamic (transactional role), and in parallel, they have institutional role respect to their affiliated companies offering support just like governments, universities, and professional associations do with their users. Thus, BAs can serve a focal company like facilitators (that drive action for this company and differentiate this from others) and balancers of innovation opportunities (which bring to the firm the knowledge that other companies are already exploiting) [7]. Likewise, BAs can create synergies between companies because they are constituted by companies with joint innovation interests and generally into the same industry [8].

In a more detailed way and as shown in Figure 1, organizations with a transactional role (with red letters in the graph) perform the purchase and sale of products and services. Vertical relations of cooperation among the clients, the focal company, and its suppliers aim to add value to the value system's product or service. On the other hand, the competitors, the focal company, and the complementors develop horizontal relations based on the competition and the complementarity of that focal company's products and services.

In institutional organizations, such as the BAs (see blue letters in Figure 1), the economic or social activities are performed. Thus, facilitators like BAs focus on helping their focal companies such as the Affiliated Companies (ACs) and increasing their opportunities. Then, ACs can create value for their current or future customers or reduce their costs. In contrast, an institutional balancing organization restricts opportunities for the focal company by reducing the value of its offer to its current or future customers or by force or induces it to increase its costs [15]. Companies and organizations that complement and facilitate the focal company's activity are generally considered facilitators that drive their creation.

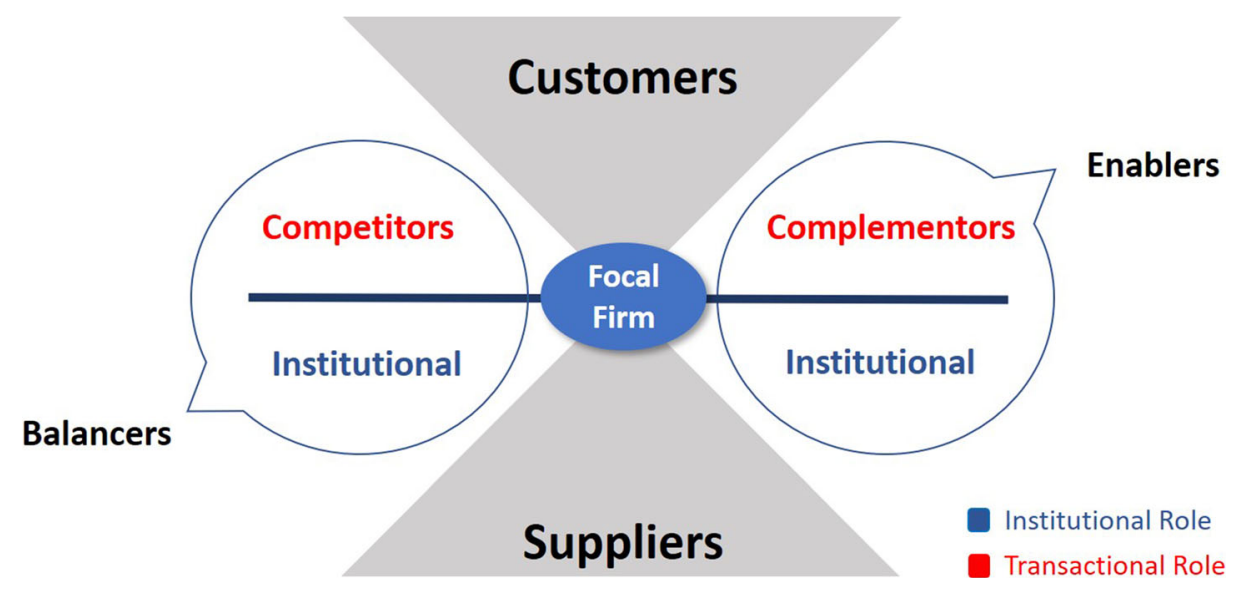

Fig. 1. Expanded value net. Based on Dalziel [15] 


\section{The Role of BA and Clusters for the CE}

CE's multiple definitions include a multi-level approach: micro, meso, and macro-level [1, 27]. The micro or enterprise level is related to the individual strategies to improve the firms' environmental performance, such as cleaner production and eco-design for improving the firms' products; the meso level refers to integrating firms' processes and material loops with other stakeholders. Thus, CE implementation at the meso-level implies developing ecoindustrial parks, networks [28, 29], clusters, and BAs [30]. Furthermore, the integration among actors is not limited to IS among companies. It also includes consumers through user dimension eco-innovations [31] like platforms to share goods and services with others to slash the unbridled consumerism and their ecological footprint. Online platforms support most integrations (e.g., Blablacar, Airbnb) and social networks (e.g., Greenapes). Finally, the macro-level is focused on regional actions that are usually encouraged by governments and institutions as developing eco-cities, eco-municipalities, or eco-provinces [32].

From an organizational perspective or micro-level, the CE can be applied as a firms' strategy. In this way, the three strategy levels (corporate, business, and functional levels) proposed by Hoffer and Schendel [33] can be applied for implementing CE: In a corporatelevel strategy, the firm should think about how and where it must grow. For that reason, it could make decisions about the relationship between product and the market, the internationalization, the business model design, cooperation and alliances opportunities, merges and acquisitions, and vertical and horizontal integration. Thus, it is necessary to apply the best practices related to $\mathrm{CE}$ that correspond to this level, such as IS, open and collaborative innovation, Industry 4.0 technologies, and Corporate Social Responsibility considerations, to define a particular circular business model.

At the business level, the strategies focus on how to compete by defining the value proposition attributes in turn of sustainable goods and services and associated prices. Therefore, it is relevant to consider the impact of product life cycle, biomimicry, and cradle-to-cradle design strategies towards creating green products for responsible consumers. Moreover, it is essential to use sustainable products, dematerialization, eco-labeling, and environmental certification, among other practices.

Then, at the functional level, the two previous levels should have been previously implemented. At this level, companies must contemplate sustainable challenges as, for example, operations should include optimization models on the consumption of energy, materials, and water to reduce the ecological footprint. Likewise, the manufacturing area must change to lean manufacturing and technological modernization.

In this sense, BAs and clusters have a crucial role in promoting the $\mathrm{CE}$ as a corporate strategy to develop sustainable technology, infrastructure, products, and services inside their ACs $[30,34]$. BAs can be an essential change agent for adopting CE among their companies because they play institutional and transactional roles. Additionally, BAs share a direct relationship with many firms of multiple sizes, and BAs have an objective perspective because they are not competitors. Consequently, BAs and industrial park managers play a central role in driving their companies' business performance through IS initiatives. Even more, it is considered one of the most critical emerging circular jobs [35].

Multiple initiatives as the BA of tanners in Lombardy and EYDE cluster in Norway [36, 37] have proven that if companies share resources exchange and "waste" within them, or with one another, they can minimize their impact on the environment, increase their profits, and encourage those around them. Moreover, BAs that produce specific materials, such as The 
Canadian Plastics Industry Association (CPIA), entered an economic transaction to become part of the Chemistry Industry Association of Canada (CIAC). Thus, the CPIA became a new plastics division created under the CIAC banner to create synergies in the sector and work towards sustainability strategies to recycle and recover plastics from landfills [38]. Moreover, the government and institutional support may accelerate the regional integration projects and feasible pilots, such as the National Industrial Symbiosis Programme (NISP) in the UK [39], and it inspired similar programs in other countries.

Nevertheless, the IS faces some barriers: the low commitment to sustainable development, information about residue streams among firms, cooperation among key actors, technical resources and feasibility, regulation, and policy that support waste recovery, community awareness of environmental issues, and economic feasibility [40].

\section{The Role of Agri-business Associations in Spain for CE}

The BAs of this study belong to the agricultural crop sector, which is a productive or primary activity that obtains raw materials of plant origin through cultivation. It is one of the most important economic activities in rural areas. Along with the livestock sector, the agricultural crop sector is part of the agro-industrial sector. The agro-industrial sector includes products from agriculture and can be used for food for humans or animals (e.g., potatoes or wheat) or industry (for example, rubber or cotton). This concept should not be confused with others such as agricultural production (which includes, for example, livestock activity) or rural production (which would include agricultural products, but also industrial or artisan products, for example).

Therefore, the World Bank has shown that Spain has 52.6\% agricultural land [41], and specifically, in Navarra (a region in the northeast of the country), there is a cultivated area of $405,194.6$ ha represents $39.4 \%$ of the total territory. Most of this surface, $76.6 \%$, corresponds to rainfed areas and the remaining $23.4 \%$ to irrigated land for vegetables, fruits, vineyards. It is well known for its asparagus [42], and even colloquially, people call it the Kingdom of vegetables. The region has progressed with ECOCIRPLAS 2020, coordinated and driven by UCAN and other crops BAs like Grupo AN and UAGN. This project aims to implement the $\mathrm{CE}$ in the sector and reduce plastic and substitution by biodegradable materials [43].

Empirical evidence shows some examples of circular practices in the productive processes, the waste generated can be used for compost [44], the generation of bioethanol and biogas[45], animal feed production based on waste[46], and cereal residues as forage for roofing, for bedding of the stables [47]. In distribution, it is possible to change the products' packaging to make transportation more efficient and economical, adapt the packaging to the product, and communicate its sustainability (E.g., "Happy eggs" ecofriendly packaging, made of heat pressed hay), optimize distribution routes, etc. [48]. Other practices can be used to close cycles of resources, such as irrigation water that can be reused [49].

\section{Methods}

Regarding the research question, this work takes the form of an exploratory case study of the BA named UCAN (Agro-industrial Union of Cooperatives of Navarra), which has promoted CE among its ACs. UCAN was founded on January 20, 1987, but with origins in the Catholic, 
Social Federation founded in 1910. The 137 Cooperatives associated with UCAN add up to more than 1,125 million euros, more than 20,000 members, and about 2000 employees [50].

The exploratory case study aims to broaden the understanding of social phenomena considered complex [51]. This approach may be justified when the terrain is poorly known, as in this case [52].

The entire case study was qualitative, and the companies participating in the study were required to answer a survey at the beginning and be willing to participate throughout the whole process. Therefore, the 15 companies that create more than $10 \%$ of the BAs' employees participated in the survey and the focus group session that included a serious game performance. Serious games are designed to ease learning and memorizing by proposing fun activities that introduce specific topics from a field of study and are usually supported by technology [1]. The idea of making a game arose because, at the time of the first survey (the results of which are detailed below), it was evident that the BAs did not know the meaning or the opportunities offered by the circular economy. Moreover, there was little dissemination of the subject in Spain up to that moment, and the research team expects to call the BAs' attention successfully.

The BA plays a key intermediary role and is the main driver of the $\mathrm{CE}$ among companies. It brings companies together and, with the help of the University, brings the CE closer to companies through awareness-raising and opportunity-seeking day in 2016. It then works hand in hand with the companies supporting business initiatives and driving new CE projects, such as the ECOCIRPLAS 2020 project mentioned above. As a result, the research analyzes the evolution of five different companies from UCAN, taking data in 2016 and four years later (Figure 2). Data for this study were collected using a survey in 2016 and 2020 that considers the six CE fields of action (Take, make, distribution, use, recovery, and IS [53] and a focus group made of brainstorming and a serious game with the UCAN.

\section{Survey Design and Follow-Up After 4 Years}

A survey involves collecting information from individuals through mailed questionnaires, telephone calls, personal interviews, etc., about themselves or the social unit they belong to [54]. This survey had several objectives:

- The company that responded to the survey knew some actions involved in the CE, so training was given through the questionnaire itself.

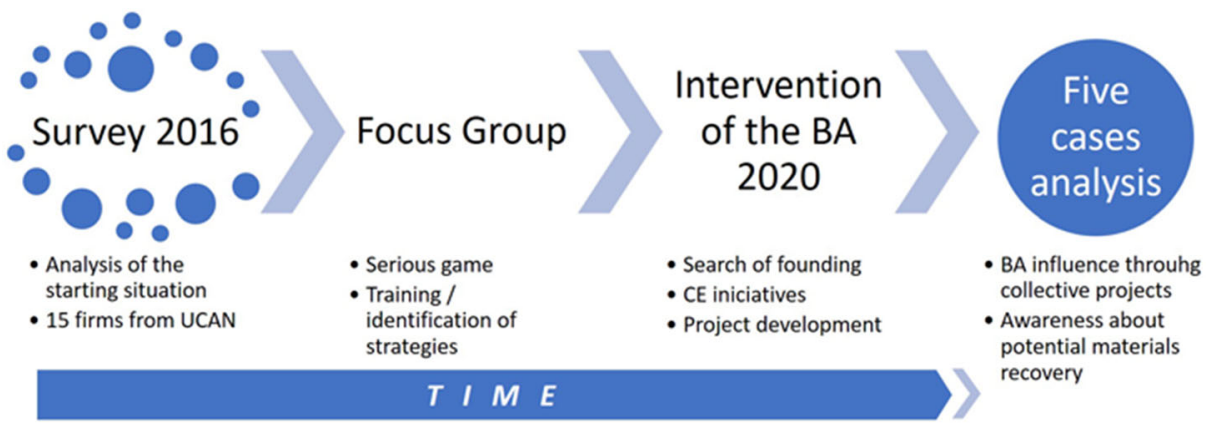

Fig. 2 Methodological processes of the UCAN case and its ACs 
- To evaluate the situation in which the company found itself concerning the CE, and at the same time, it served the company to ask itself about possible actions that they were not considering but that they could implement.

- To diagnose how well implemented the $\mathrm{CE}$ was in the agro-food sector and compare some companies four years later.

A total of 15 companies took the diagnostic questionnaire of 129 companies that the association has. The survey obtained detailed information on a small number of BAs and identified BAs willing to participate and learn about $\mathrm{CE}$. In addition, the survey would allow us to know the progress of these BAs in the future. The questionnaire had two parts: The first part consisted of general information about the companies and the second part had specific questions about the fields of action: take, make, distribute, use, recover, and IS [55]. Most of the questions required a response on a 7-point Likert scale, and some questions allowed open-ended responses. Therefore, a broad scale was defined to discover more different degrees of opinion that could help understand the level of knowledge and implementation of CE.

A similar survey was carried out four years later among five agro-industrial companies from the initial group to track their CE implementation progress, the current opportunities, and barriers. This is why we have waited to publish the 2016 results until we could follow up with some of the companies that initially participated. Moreover, being a voluntary study, without financial rewards, the surveys carried out four years later depending on the intrinsic motivation of the BAs to collaborate and share their perspective.

\section{Focus Group}

To bring CE closer to agri-food companies, a focus group was carried out on May 30, 2016, to collaborate with the UCAN association in Pamplona, Spain. The Focus Group research method consists of bringing together a group of experts to discuss and analyze reactions to a given topic, gathering a large amount of qualitative information in a relatively short period. This method is advantageous and appropriate for social research, such as the one related in this case. [56].

The purpose of this work session was to identify opportunities for implementing the CE in agro-industrial processes. Nineteen people from 15 organizations like wineries and agri-food cooperatives from Navarra participated in the work session. The focus group was organized in three steps. First, the participants received a brief theoretical introduction about the Circular Economic fundaments and potential sector opportunities. A serious game was then played to delve into concepts of the CE, stimulate the participants' creativity, and generate ideas about possible opportunities in their organizations. Finally, the participants worked in groups on identifying the processes most likely to generate environmental improvements, the actions, and strategies that could be carried out in the participating companies in the short, medium, and long term.

\section{Serious Game "EcoParty"}

The use of serious games has been explored in different contexts as a valuable tool to promote sustainability training $[57,58]$. Therefore, the research team developed this game based on their own experience in table games and sustainability lectures to improve the companies' knowledge level after successfully passing specific tests aimed at the CE fundamentals. 
The 19 participants played organized in teams of 4 to 5 people in two phases. They began with a "warm-up round"; The starting team chose one of the cards from the warm-up round. Then, the team had to correctly perform the test to keep the turn and play again; otherwise, the next team had to continue. The questions in this round were of the true or false type and short questions. The second phase sought to develop analytical thinking and get participants to reflect on opportunities in their sector. The categories that were designed for the tests were the following:

- Guess What I do: This test aims to develop behavioral knowledge. A situation was presented, and three possible actions or attitudes to face said situation. One team player had to choose one of the three actions, and the rest of the team must guess. They all had to consult it and had only one chance to guess the action.

- Telepathy: This activity helps to propose circular solutions. Two players from the same team separately wrote something related to what was proposed on the card, and their answers had to coincide. For example, "With the crops waste, you can make..."; both must have written "compost".

- What will it be?: This test motivates the circular economy conceptual learning as well as the following tests. A question was posed with several options. Some points were won in case of success, but x / 2 was removed in the "wrong answer". Thus, you could not respond and lose your turn.

- Do you know it?: A question was posed with an answer and questions about definitions.

- Draw it: A player was asked to draw what was described on the card that needed to be guessed by the rest of the team members, adhering to the established time.

- True or False: It had to be decided if the statement made was true or false. In case of failure, there was a penalty of one or two points over two.

- Shape it!: This test develops a shared vision of circular economy fundaments. The description on the card had to be molded with plasticine. A few cards needed a complement, which was a "product card." Another team member removed this second card to supplement the information on the first card.

\section{Results and Discussion}

\section{CE Progress in Agro-industrial Firms After Four Years}

The five companies that responded to the call have less than 10 employees, and belong specifically to the agriculture sector and the wine industry. Considering the trajectory and the current situation of the five monitored cases, the results were analyzed according to the six CE fields of action [59] and presented in Table 1. In the "Take" field, the current study found that agro-industrial cooperatives do not demand any environmental certification from their suppliers/agricultural companies and consider that most of them comply with the environmental legislation (80\%). However, at least half of the cooperatives have criteria to reduce raw materials, water, or energy to design and improve production processes. Moreover, cooperatives must comply with traceability systems. The focus group in 2016 showed a high interest in improving energy efficiency and increased sustainable energy supply, but the high-cost investments are still a challenge. 
Table 1 AC assessment based on CE fields of action. Likert scale from 1 to 7

Please rate from 1 to 7 the compliance with environmental legislation by your suppliers $\begin{array}{llll}3.8 & 5 & 24 \%\end{array}$

Do you have environmental purchasing criteria in the selection of suppliers?

$3.6 \quad 3.6 \quad 0 \%$

Does the company have environmental criteria to reduce the consumption of raw

$4.2516 \%$

materials, water, or energy in the design and improvement of its production processes?

How much do you consider that the materials used in production are designed to be $\begin{array}{llll}4.2 & 3 & -40 \%\end{array}$ biodegradable?

How much do you consider that the NON-biodegradable materials used in production $3.8 \quad 5 \quad 24 \%$ are designed for reuse, recycling or remanufacturing?

* Does the company offer after-sales repair services that extend the life of the products? $\quad \begin{array}{llll}1.75 & 3.5 \quad 50 \%\end{array}$

* Do you promote or facilitate any type of maintenance manual to extend the useful life $4 \quad 5 \quad 20 \%$ of your products?

Does the company use energy from the recovery and use of waste heat?

Does the company use treatments (filtering, soaking, among others) to extend the use of 1.8 industrial resources such as oils, acids, lubricants, etc.?

Does the company carry out any maintenance process to extend the use of materials such as plastics, tools, canvas, etc?

Does the company take back the products that its customers no longer use?

Does the company sell the industrial material it generates (Sub chemicals, oils, packaging, plastics, etc.)?

Does the company rent or share equipment or facilities?

Does the company receive any kind of advice or financial aid from public institutions to promote environmental management?

Please rate from 1 to 7 how much do you consider that UCAN promotes integration for environmental management among collaborating companies

$\begin{array}{lll} & 2 & \text { NA } \\ 4.4 & 6.4 & 31 \% \\ 2.2 & 1.8 & -22 \% \\ & & \\ 1.8 & 1.2 & -50 \% \\ 2 & 2.2 & 9 \% \\ & 4.8 & \text { NA }\end{array}$

Then, in the "make," on average, the organizations analyzed went from a rating of 3.5 over 7 in 2016 to 5 over 7 in 2020. Considering that the technical materials (non-biodegradable) used in production are designed for reuse, recycling, or remanufacturing, the five companies analyzed consider that the environmental management of their organization has improved by approximately $24 \%$ over the last four years, in which their most common strategies have to do with the implementation of recycling and waste collection. Furthermore, $80 \%$ of companies do not consider that the world's pandemic has delayed or negatively influenced their environmental management.

Four years ago, four of the five companies did not know the CE meaning. Today, all five companies know the term and have recognized it in the media. Then, most companies sporadically had some environmental criteria for selecting suppliers, and today, it is more common.

Likewise, the criteria for reducing raw materials consumption have increased in their frequency of implementation by approximately $16 \%$. Among the five cases analyzed, they considered that the materials used in production were $60 \%$ biodegradable. Surprisingly, that consideration figure has dropped by almost $40 \%$ (1.2 points), possibly due to increased knowledge about materials. The increase in knowledge may explain that the five companies analyzed consider that $70 \%$ of the production materials are reusable, $20 \%$ more than four years ago.

In the "Distribute" field of study, the cooperatives expect to optimize stocks and routes, local market promotion. Besides, digitization is considered a way to facilitate distribution/ communication with suppliers and reverse logistics. 
Then, the "recovery" field consists of value recovering opportunities from biological waste. Although companies are dedicated to agro-industrial production, such as preserves and wines, they have recognized that packaging as part of their products can be recovered after customers no longer use it. Nonetheless, in general, the analyzed firms rarely use energy from the recovery, use waste heat or use treatments to extend industrial resources, and seldom rent or share equipment or facilities.

Finally, IS is considered a possible opportunity to share resources and infrastructure. Cooperatives also believe that European financial incentives would provide founding capital to start productive and profitable waste recovering activities.

\section{CE Opportunities and Barriers for Agro-industrial Companies}

The maturity of knowledge about CE and the development of related projects at UCAN has led companies to perceive cost reduction as the most important benefit of implementing the CE. Four years ago, the focus group showed that most organic wastes were already valorized without giving them added value to avoid management costs (Table 2). In contrast, after four years, companies recognize that being more sustainable generates more profits. Another benefit that the participants did not recognize is prestige, it is currently valued at 3 out of 7 , and environmental considerations were downplayed, possibly because they prioritize profitability (Table 2).

Surprisingly, the pandemic is not considered a barrier to implementing CE. On the other hand, it is considered that the commitment of the organization's leaders can be decisive in the implementation or not of the CB. The other barriers that four years ago had high marks, such as the lack of capital and technology, have lost importance in the organization's perception; it is to say, they see it as a less complicated change. Four years ago, in the focus group, the firms claimed that they would like to use biodegradable plastic and other sustainable materials, but it was expensive and technically challenging. However, the evaluated companies' managers show a clear interest in the sustainable sourcing of materials, see the economic benefits of CE, and have obtained funding to carry out $\mathrm{CE}$ implementation projects. This is how the interest in reducing and recovering the plastic used in the sector has increased since it reduces the environmental impact of agro-industrial production and increases companies' profitability.

Table 2 Perceived benefits and potential barriers to CE. Likert scale from 1 to 7

\begin{tabular}{llll}
\hline Perceived benefits & $\mathbf{2 0 1 6}$ & $\mathbf{2 0 2 0}$ & Variation \\
Increase in prestige & $\mathrm{DK}$ & 3 & $52 \%$ \\
Cost reduction (Profits $€$ ) & 2 & 4.2 & $-18 \%$ \\
Environmental recovery, at least at the local level & 4.5 & 3.8 & $-25 \%$ \\
Guarantee the permanence of the company over time & 4 & 3.2 & Variation \\
Potential barriers & $\mathbf{2 0 1 6}$ & $\mathbf{2 0 2 0}$ & NA \\
*COVID 19 & 5 & 3.8 & $-4 \%$ \\
Lack of financial aid & 5.8 & $4.5 \%$ \\
Insufficient information management systems & 6.5 & 4.6 & $-20 \%$ \\
Lack of appropriate technology & 5.5 & 4.8 & $-25 \%$ \\
Insufficient financial resources & 6 & 4.7 & $4 \%$ \\
Lack of customer interest in the environment & 4.5 & 4.6 & $-20 \%$ \\
Lack of support from public institutions & 5.5 & 3.6 & $-39 \%$ \\
Lack of qualified personnel in environmental management & 5 & 3.8 & $8 \%$ \\
The commitment of the organization's leaders & 3.5 & & \\
\hline
\end{tabular}


Moreover, cooperatives think that Industry 4.0 technologies and firms' digitization can help them develop resource-efficient and less expensive processes.

\section{BAs as CE Intermediaries}

Figure 3 proposes a methodology of BAs to boost the CE among its ACs. This methodology is based on UCAN's experience and the steps to become an intermediary for CE and IS implementation. The methodology proposes that, first, BAs are responsible for connecting ACs and matching CE interests and opportunities. Then, BAs should provide additional information to the ACs to bring them together, drive collaborative relationships, and generate synergies to connect their nutrients, infrastructure, knowledge, and waste. In this case, the serious game was a key tool to raise awareness and know the CE's fundamental concepts among companies that did not know anything about it. In fact, in 2016, none of the UCAN companies knew clearly what CE was, the opportunities or challenges it would imply for their organizations. The Serious Game helped teach CE concepts to agricultural companies who probably have experience but not technical knowledge in sustainability and create a creative and trust-based environment.

However, BAs generally must obtain resources independently to carry out eco-innovation projects, leverage their ACs, and finance their activities as a CE intermediary. That behavior is

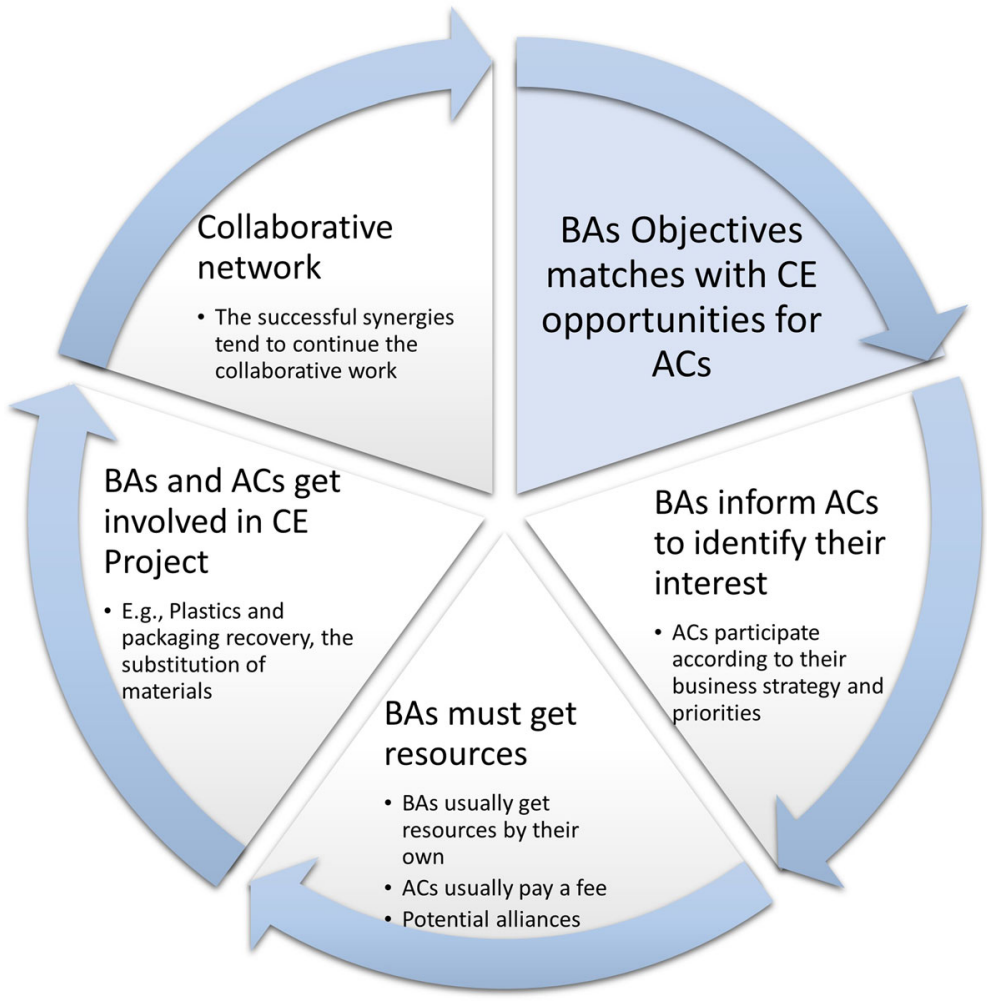

Fig. 3 BAs methodology to boost the CE among their ACs 
advantageous for an individual organization with no financial resources or knowledge to implement the $\mathrm{CE}$ alone.

The BAs' synergy network then enables alliances with other associations and universities and encourages the flow of materials to follow different paths between companies as conditions change. As trust and collaboration relationships evolve, the process is iterative, and it must be restarted to advance in the aspects that become strategic for the ACs and increase their level of innovation and competitiveness in the market.

\section{Conclusion}

As a nature-based metaphor, BAs' role as intermediaries for CE development is similar to leaves. BAs act like the central vein of a leaf running through the center, transporting water to photosynthetic cells and sugars away from them. In this case, the secondary veins (ACs) branch off from the central vein and remain connected. Thus, the flow of nutrients is quickly redirected to any other vein to restore it or change the nutrients flow [60]. Thus, it can be said that BAs function as the central vein of each sector by facilitating IS with materials loops. Companies, mainly SMEs, often find themselves without sufficient research or training resources in essential subjects such as the CE and IS since it escapes them from their daily activities. For this reason, BAs can provide critical support to these companies, showing them the importance of implementing the $\mathrm{CE}$ in their organizations and making the necessary knowledge available to companies.

This study proposes a BAs methodology to boost the CE among ACs based on the UCAN performance as CE intermediary and its ACs' progress in the field. After UCAN proposed the $\mathrm{CE}$ as a critical strategy for ACs in 2016 with the diagnostic survey and the serious game, the analyzed companies recognized the $\mathrm{CE}$ as a value creation strategy considering benefits like profits and prestige increase. Likewise, the BAs' potential to promote the closure of energy and materials cycles in regions and business sectors such as agro-industry is demonstrated. BAs and ACs can develop the proposed methodology autonomously; however, the accompaniment of a university, research center, or consulting firm can accelerate the process and complement it with other implementation techniques or tools.

Moreover, this long-term study demonstrated an improved perception of economic benefits and reduced barriers to implementing CE. Among the main opportunities for improvement identified, the potential for improving energy efficiency in its processes was discussed, including using renewable energies and agricultural by-products and improving the search for synergies between cooperatives and organizations. In addition, it is considered that progress can be made to share information, infrastructure, and resources.

At a methodological level, it is also evident that the involvement of local universities with companies and the development of research with practical relevance is essential for $\mathrm{CE}$ implementation. This study shows the importance of qualitative methodologies and serious games in companies, cooperatives, and BAs to broaden knowledge and concern for the environmental aspect. This study also shows the importance of evaluating CE awareness in the long term in BAs such as UCAN to understand the knowledge transfer from academic initiatives better.

This study has some limitations, characteristic of this type of research. First, it has been limited to a small number of companies within a BA, so it would be convenient to replicate this study in other types of different associations. Second, the geographical and sectorial area is 
also specific, so it would be interesting to confirm the conclusions in other sectors and different geographical areas. Finally, future research would present new methodological pathways to link BAs from different sectors, using a bigger group of participants or other institutional organizations as $\mathrm{CE}$ intermediaries to encourage the IS for CE implementation.

Acknowledgements The article is based on research funded by the Spanish National Programme for Fostering Excellence in Scientific and Technical Research and The European Regional Development Fund: DPI201570832-R (MINECO/FEDER), the Project "Desafíos y oportunidades de la implementación de la Economía Circular en las empresas" sponsored by Pontificia Universidad Javeriana ID00009299. The authors are grateful for the UCAN support and collaboration. In addition, the authors appreciate the support from Maria Paz Vargas, undergraduate research assistant, Pontificia Universidad Javeriana.

Code Availability 'Not applicable' for that section.

Author Contribution This paper is the result of teamwork. Vanessa Prieto-Sandoval, Andres Mejia-Villa, Carmen Jaca, and Marta Ormazabal conceptualized and designed the research. Marta Ormazabal designs the methodology and focus group design and Andres Mejia-Villa. Vanessa Prieto-Sandoval and Andres Mejia-Villa analyzed the data and discussed the results. Vanessa Prieto-Sandoval, Andres Mejia-Villa, Carmen Jaca, and Marta Ormazabal wrote the paper.

Funding 1. Spanish National Programme for Fostering Excellence in Scientific and Technical Research and The European Regional Development Fund: DPI2015-70832-R (MINECO/FEDER)

2. The Project "Desafios y oportunidades de la implementación de la Economía Circular en las empresas" sponsored by Pontificia Universidad Javeriana ID00009299.

Data Availability The data that support the findings of this study are available on request from the corresponding author, [Prieto-Sandoval]. The data are not publicly available due to their containing information that could compromise research participants' privacy.

\section{Declarations}

Competing Interests The authors declare no competing interests.

\section{References}

1. Prieto-Sandoval V, Jaca C, Ormazabal M (2018) Towards a consensus on the circular economy. J Clean Prod 179:605-615. https://doi.org/10.1016/j.jclepro.2017.12.224

2. Ormazabal M, Prieto-Sandoval V, Santos J, Jaca C (2020) Guiding SMEs towards the circular economy: case study. In: Salomone R, Cecchin A, Deutz P et al (eds) INDUSTRIAL SYMBIOSIS: Advancing the Circular Economy Industrial Symbiosis: Advancing the Circular Economy. Springer, Berlin, pp 27-41

3. Chertow MR (2000) Industrial symbiosis : literature and taxonomy. Annu Rev Energy Environ 25:313-337. https://doi.org/10.1146/annurev.energy.25.1.313

4. Cecchin A, Salomone R, Deutz P, Raggi A, Cutaia L (2020) Relating industrial symbiosis and circular economy to the sustainable development debate. In: Salomone R, Cecchin A, Deutz P et al (eds) Industrial Symbiosis for the Circular Economy: Operational Experiences, Best Practices and Obstacles to a Collaborative Business Approach. Springer International Publishing, Cham, pp 1-25

5. Berkowitz H, Dumez H (2016) The concept of meta-organization: issues for management studies. Eur Manag Rev 13:149-156. https://doi.org/10.1111/emre.12076

6. Daddi T, Iraldo F (2015) The effectiveness of cluster approach to improve environmental corporate performance in an industrial district of SMEs: a case study. Int J Sustain Dev World Ecol:1-11. https:// doi.org/10.1080/13504509.2015.1106988 
7. van Hoof B, Duque-Hernández J (2020) Supply chain management for circular economy in Latin America: RedES-CAR in Colombia. In: Salomone R, Cecchin A, Deutz P et al (eds) Industrial Symbiosis for the Circular Economy. Springer, Berlin

8. Cervantes G, Torres LG, Ortega M (2020) Valorization of agriculturalwastes and biorefineries: a way of heading to circular economy. In: Industrial Symbiosis for the Circular Economy: Operational Experiences, Best Practices and Obstacles to a Collaborative Business Approach. Springer, Berlin, pp 181-194

9. Alfaro JA, Mejía-Villa A, Recalde M, Rodriguez-Ferradas MI (2017) Las asociaciones empresariales como motores de la innovación estratégica en las empresas [Business associations as drivers of strategic innovation in companies]. EUNSA, Pamplona, España

10. van Lente H, Hekkert M, Smits R, van Waveren B (2003) Roles of systemic intermediaries in transition processes. Int J Innov Manag 07:247-279. https://doi.org/10.1142/S1363919603000817

11. Gassmann O, Daiber M, Enkel E (2011) The role of intermediaries in cross-industry innovation processes. R D Manag 41:457-469. https://doi.org/10.1111/j.1467-9310.2011.00651.x

12. Howells $\mathbf{J}$ (2006) Intermediation and the role of intermediaries in innovation. Res Policy 35:715-728. https://doi.org/10.1016/j.respol.2006.03.005

13. Marques JC (2017) Industry business associations: self-interested or socially conscious? J Bus Ethics 143: 733-751. https://doi.org/10.1007/s10551-016-3077-y

14. Aranda-Usón A, Portillo-Tarragona P, Marín-Vinuesa LM, Scarpellini S (2019) Financial resources for the circular economy: a perspective from businesses. Sustainability 11. https://doi.org/10.3390/su11030888

15. Dalziel M (2007) Games of innovation: the roles of nonprofit organisations. Int J Innov Manag 11:191-214. https://doi.org/10.1142/S1363919607001679

16. Dalziel M (2006) The impact of industry associations: evidence from Statistics Canada data. Innovation 8: 296-306. https://doi.org/10.5172/impp.2006.8.3.296

17. Miller R, Floricel S (2007) Games of innovation: a new theoretical perspective. Int J Innov Manag 11:1-35. https://doi.org/10.1142/S1363919607001606

18. Hutson N (2016) Exploring the institutional work of an industrial association in the greening of industry sectors. 12th Corporate Responsibility Research Conference 1-27

19. Watkins A, Papaioannou T, Mugwagwa J, Kale D (2015) National innovation systems and the intermediary role of industry associations in building institutional capacities for innovation in developing countries: a critical review of the literature. Res Policy 44:1407-1418. https://doi.org/10.1016/j.respol.2015.05.004

20. Athreye S, Chaturvedi S (2007) Industry associations and technology-based growth in India. Eur J Dev Res 19:156-173. https://doi.org/10.1080/09578810601144426

21. Lucas J (1993) State and society in Nigeria: a study of business associations in Kano. Indiana University, Bloomington

22. Nadvi K, Schmitz H (1994) Industrial clusters in developing countries: review of experiences and research agenda. In: Discussion Paper No. 339. Institute of Development Studies. University of Sussex, Brighton

23. Agosin MR, Urzúa S, Wagner R, et al (2014) ¿Cómo repensar el desarrollo productivo?: Políticas e instituciones sólidas para la transformación económica. BID

24. Damsgaard J, Lyytinen K (2001) The role of intermediating institutions in the Diffusion of Electronic Data Interchange (EDI): how industry associations intervened in Denmark, Finland, and Hong Kong. Inf Soc 17: 195-210. https://doi.org/10.1080/01972240120907

25. Heidenheimer AJ, Langdon FC (2012) Business associations and the financing of political parties: a comparative study of the evolution of practices in Germany, Norway and Japan. Springer Science \& Business Media, Berlin

26. Kautto P (2007)Industry-government interaction in the preparation of a new directive: Nokia, industry associations and EuP. Environ Policy Gov 17:79-91

27. Kirchherr J, Reike D, Hekkert M (2017) Conceptualizing the circular economy: an analysis of 114 definitions. Resour Conserv Recycl 127:221-232. https://doi.org/10.1016/j.resconrec.2017.09.005

28. Zhu Q, Geng Y, Sarkis J, Lai K-H(2015) Barriers to promoting eco-industrial parks development in China: perspectives from senior officials at National Industrial Parks. J Ind Ecol 19:457-467. https://doi.org/10. $1111 /$ jiec. 12176

29. Oguntoye O, Geissdoerfer M, Nuwarinda H, Evans S (2019) Facilitating industrial symbiosis programmes in developing countries: reflections from Gauteng, South Africa. Dev Pract 29:115-121. https://doi.org/10. $1080 / 09614524.2018 .1527289$

30. UN Global Compact, Chung DW, Liu L, et al (2015) Contributions of Business Associations and Sector Initiatives

31. Carrillo-Hermosilla J, Del Río P, Könnölä T (2010) Diversity of eco-innovations: Reflections from selected case studies. J Clean Prod 18:1073-1083. https://doi.org/10.1016/j.jclepro.2010.02.014

32. Yuan Z, Bi J, Moriguichi Y, Yuan (2006) The circular economy: a new development strategy in China. J Ind Ecol 10:4-8. https://doi.org/10.1162/108819806775545321 
33. Hoffer CW, Schendel D (1978) Strategy formulation. Analytical concepts, St. Paul

34. Hong J, Li X (2013) Speeding up cleaner production in China through the improvement of cleaner production audit. J Clean Prod 40:129-135. https://doi.org/10.1016/j.jclepro.2012.09.024

35. EHORE, Circle Economy (2017) Circular jobs: understanding employment in the circular economy in the Netherlands. 10

36. Daddi T, Nucci B, Iraldo F (2017) Using Life Cycle Assessment (LCA) to measure the environmental benefits of industrial symbiosis in an industrial cluster of SMEs. J Clean Prod 147:157-164. https://doi.org/ 10.1016/j.jclepro.2017.01.090

37. EYDE, NCE (2019) Norwegian opportunities within Lithium-ion batteries

38. Canadian Plastics (2020) CPIA to dissolve, regroup under Chemistry Industry Association umbrella. Canadian Plastics

39. Paquin R, Howard-Grenville J (2009) Facilitating regional industrial symbiosis: network growth in the UK's national industrial symbiosis programme. Soc Embeddedness Ind Ecol 103-127. https://doi.org/10. 4337/9781848449060.00014

40. Golev A, Corder GD, Giurco DP (2015) Barriers to industrial symbiosis: insights from the use of a maturity grid. J Ind Ecol 19:141-153. https://doi.org/10.1111/jiec.12159

41. World Bank (2016) Food and Agriculture Organization, electronic files and web site. https://data. worldbank.org/indicator/AG.LND.AGRI.K2?end=2016\&locations=ES\&start=1961\&view=chart. Accessed 3 Nov 2020

42. Vicente AM, Donézar M (2004) Memoria de Mapa de cultivos y aprovechamientos de Navarra. Departamento de Agricultura, Ganadería y Alimentación del Gobierno de Navarra, Pamplona

43. UCAN, UAGN, Grupo AN, et al (2020) Ecocirplas project

44. Martínez-Blanco J, Lazcano C, Christensen T et al (2013) Compost benefits for agriculture evaluated by life cycle assessment. A review. Agron Sustain Dev 33:721-732. https://doi.org/10.1007/s13593-013-0148-7

45. Kaparaju P, Serrano M, Thomsen AB, Kongjan P, Angelidaki I (2009) Bioethanol, biohydrogen and biogas production from wheat straw in a biorefinery concept. Bioresour Technol 100:2562-2568. https://doi.org/ 10.1016/j.biortech.2008.11.011

46. Walker P (2000) Food residuals: waste product, by-product, or coproduct. In: Food Waste to Animal Feed. John Wiley \& Sons, Ltd, Hoboken, pp 17-30

47. Lizotte P-L, Savoie P (2013) Spring harvest of corn stover for animal bedding with a self-loading wagon. Appl Eng Agric 29:25-31. https://doi.org/10.13031/2013.42530

48. Wakeland W, Cholette S, Venkat K (2012) Food transportation issues and reducing carbon footprint. In: Boye JI, Arcand Y (eds) Food Engineering Series, p E1

49. Tran QK, Schwabe KA, Jassby D (2016) Wastewater reuse for agriculture: development of a Regional Water Reuse Decision-Support Model (RWRM) for cost-effective irrigation sources. Environ Sci Technol 50:9390-9399. https://doi.org/10.1021/acs.est.6b02073

50. UCAN (2021) Presentación. https://ucan.es/quienes-somos/presentacion-2/. Accessed 26 Mar 2021

51. Ogawa RT, Malen B (1991) Towards rigor in reviews of multivocal literatures: applying the exploratory case study method. Rev Educ Res 61:265-286

52. Boton C, Forgues D (2018) Practices and processes in BIM projects: an exploratory case study. Adv Civil Eng 2018:1-12. https://doi.org/10.1155/2018/7259659

53. Jaca C, Ormazabal M, Prieto-Sandoval V et al (2019) Circular economy — guide for SMEs. EUNSA, Pamplona, España

54. Rossi PH, Wright JD, Anderson AB (1983) Handbook of Survey Research. Academic press

55. Ormazabal M, Prieto-Sandoval V, Jaca C, Santos J (2016) An overview of the circular economy among SMEs in the Basque Country: a multiple case study. J Indust Eng Manag 9:1047-1058. https://doi.org/10. 3926/jiem.2065

56. Barkemeyer R, Holt D, Preuss L, Tsang S (2014) What happened to the 'development' in sustainable development? Business guidelines two decades after Brundtland. Sustain Dev 22:15-32. https://doi.org/10. 1002/sd.521

57. Saitua-Iribar A, Corral-Lage J, Peña-Miguel N (2020) Improving knowledge about the sustainable development goals through a collaborative learning methodology and serious game. Sustainability 12:156169. https://doi.org/10.3390/su12156169

58. Ouariachi T, Gutiérrez-Pérez J, Olvera-Lobo M-D (2018) Can serious games help to mitigate climate change? Exploring their influence on Spanish and American teenagers' attitudes / ¿Pueden los serious games ayudar a mitigar el cambio climático? Una exploración de su influencia sobre las actitudes de los adolescentes españoles y estadounidenses. PsyEcology 9:365-395. https://doi.org/10.1080/21711976.2018. 1493774 
59. Prieto-Sandoval V, Ormazabal M, Jaca C, Viles E (2018) Key elements in assessing circular economy implementation in small and medium-sized enterprises. Bus Strateg Environ 27:1525-1534. https://doi.org/ $10.1002 /$ bse. 2210

60. Katifori E, Szöllosi GJ, Magnasco MO (2010) Damage and fluctuations induce loops in optimal transport networks. Phys Rev Lett 104:1-4. https://doi.org/10.1103/PhysRevLett.104.048704 